\title{
Rivaroxaban for Preventing Venous Thromboembolism in High-Risk Ambulatory Patients with Cancer: Rationale and Design of the CASSINI Trial
}

\author{
Alok A. Khorana ${ }^{1}$ Saroj Vadhan-Raj ${ }^{2} \quad$ Nicole M. Kuderer ${ }^{3} \quad$ Ted Wun $^{4}$ Howard Liebman ${ }^{5}$ Gerald Soff ${ }^{6}$ \\ Chandra Belani $^{7}$ Eileen M. O’Reilly ${ }^{6}$ Robert McBane $^{8}$ John Eikelboom ${ }^{9}$ C.V. Damaraju ${ }^{10}$ \\ Karen Beyers ${ }^{10}$ Flavia Dietrich $^{10}$ Ajay K. Kakkar ${ }^{11}$ Hanno Riess $^{12}$ Renata D’Alpino Peixoto ${ }^{13}$ \\ Gary H. Lyman ${ }^{14}$
}

1 Cleveland Clinic, Cleveland, Ohio, United States

2 The University of Texas M.D. Anderson Cancer Center, Houston,

Texas, United States

3 University of Washington, Seattle, Washington, United States

${ }^{4}$ University of California Davis Comprehensive Cancer Center,

Sacramento, California, United States

5 University of Southern California Keck School of Medicine,

Los Angeles, California, United States

${ }^{6}$ Memorial Sloan Kettering Cancer Center, New York,

New York, United States

7 Penn State Hershey Cancer Institute, Hershey,

Pennsylvania, United States

8 Mayo Clinic, Rochester, Minnesota, United States

${ }^{9}$ McMaster University, Hamilton, Ontario, Canada

${ }^{10}$ Janssen Research and Development, Raritan,

New Jersey, United States

11 University College London and Thrombosis Research Institute, London, United Kingdom

${ }^{12}$ Charité University Hospitals, Berlin, Germany

13 Department of Medical Oncology, British Columbia Cancer Agency, Vancouver, British Columbia, Canada

${ }^{14}$ Fred Hutchinson Cancer Research Center, University of

Washington, Seattle, Washington, United States
Address for correspondence Alok A. Khorana, MD, FACP, Cleveland Clinic, 9500 Euclid Avenue/R35, Cleveland, OH 44195, United States (e-mail: khorana@ccf.org).

Thromb Haemost 2017;117:2135-2145.
Abstract
Keywords
- anticoagulation
- risk stratification
- rivaroxaban
- venous thromboembolism
- neoplasms
- prophylaxis

Venous thromboembolism (VTE) is a frequent complication of cancer associated with morbidity, mortality, increased hospitalizations and higher health care costs. Cancer patients at increased risk for VTE can be identified using a validated risk assessment score, and the incidence of VTE can be reduced in high-risk settings using anticoagulation. Rivaroxaban is a potent, oral, direct, factor Xa inhibitor approved for the prevention and treatment of thromboembolic events, including VTE. CASSINI is a double-blind, randomized, parallel-group, multicentre study comparing rivaroxaban with placebo in adult ambulatory patients with various cancers who are initiating systemic cancer therapy and are at high risk of VTE (Khorana score $\geq 2$ ). Patients with primary brain tumours or those at risk for bleeding are excluded. Approximately 700 patients will be randomized 1:1 to rivaroxaban received

March 10, 2017 accepted after revision July 1,2017
DOI https://doi.org/ 10.1160/TH17-03-0171. ISSN $0340-6245$.
Copyright () 2017 Schattauer

License terms

(ㄷ) (i) $\ominus$ () 
$10 \mathrm{mg}$ daily or placebo for up to 6 months if there is no evidence of VTE from compression ultrasonography (CU) during screening or from routine care imaging within 30 days prior to randomization. Mandatory CU will also be performed at weeks 8 and 16 ( \pm 7 days), and at study end ( \pm 3 days). The primary efficacy hypothesis is that anticoagulation with rivaroxaban reduces the composite of objectively confirmed symptomatic or asymptomatic, lower-extremity, proximal deep-vein thrombosis (DVT); symptomatic, upper-extremity DVT; symptomatic or incidental pulmonary embolism; and VTE-related death compared with placebo. The primary safety objective is to assess major bleeding events (Clinical trial information: NCT02555878).

\section{Introduction}

Venous thromboembolism (VTE), which includes deep-vein thrombosis (DVT) and pulmonary embolism (PE), is a common, life-threatening condition in many cancer outpatient populations. ${ }^{1-4}$ Patients with cancer across most common tumour types are at a four- to sevenfold greater risk for VTE compared with individuals without cancer. ${ }^{5,6}$ The risk of cancer-associated VTE varies during the course of the disease, being especially high in the first few months after diagnosis and surgical management, during systemic cancer treatment and in late-stage metastatic disease. ${ }^{5-8}$ A recent real-world retrospective analysis of a health care claims database that included 27,479 solid tumour patients reported that the rate of VTE at 3.5 months after the initiation of systemic cancer therapy was on average $7.3 \%$ (range: $4.6-11.6 \%$ ) and that the cumulative risk continued to increase to $13.5 \%$ (range: 9.8-21.3\%) at 12 months. ${ }^{9}$ The highest rate of VTE was observed among patients receiving systemic cancer therapy for tumours of the pancreas, stomach or lung. ${ }^{7-10}$

Development of VTE in patients with cancer is associated with substantial morbidity and mortality, as well as higher health care costs. ${ }^{11}$ Venous thromboembolism is the second leading cause of death in ambulatory patients with cancer. ${ }^{10}$ Furthermore, patients with cancer who develop VTE have a threefold increase in hospitalizations and length of hospital stay, as well as higher health care costs, compared with cancer patients without VTE $(p<0.0001) .{ }^{11}$ The occurrence of VTE also complicates the clinical management of cancer and may terminate or delay needed anticancer therapies.

Cancer-associated VTE occurs primarily in the outpatient setting, whereas major public health efforts to institute thromboprophylaxis have focused on the inpatient population. Previous studies of thromboprophylaxis with lowmolecular-weight heparins (LMWH) in ambulatory patients with cancer demonstrated that anticoagulation was associated with a significant relative risk reduction in VTE, although the absolute benefit was relatively modest, thereby necessitating prophylactic treatment of a large number of patients to prevent a single VTE event. ${ }^{12-15}$ Because the studies included lower-risk patients and had a relatively short duration ( $\sim 3$ to 4 months), they may not have been adequate to appropriately assess the value of prophylactic anticoagulation in outpatients with cancer and higher risk of VTE. Consequently, current clinical guidelines do not recom- mend routine outpatient VTE prophylaxis in most ambulatory patients with cancer (except for multiple myeloma and select high-risk solid tumours), ${ }^{1-4}$ because of the uncertainty regarding the overall benefit-to-risk profile in this unselected patient population.

Although cancer increases the risk for VTE, individual risk factors cannot identify high-risk patients for thromboprophylaxis. The Khorana score, which includes multiple risk factors, was derived and validated in patients initiating chemotherapy in the outpatient setting. Five risk factors were identified that were predictive of chemotherapy-related VTE (-Table 1). ${ }^{16}$ This risk score was subsequently validated in multiple settings and evaluated in more than 12,000 patients ${ }^{17-22}$ (- Table 2). ${ }^{23-37}$

Current American Society of Clinical Oncology clinical practice guidelines and other clinical guidelines recommend this score as the only validated risk assessment tool for the prediction of cancer-associated VTE in outpatients. $3,4,38,39$ The data presented in - Table 2 clearly highlight the high risk of VTE in patients with cancer and underscore the urgent need for novel therapies for primary thromboprophylaxis in this patient population.

Table 1 Modified risk stratification model for cancer-associated VTE in the ambulatory setting (Khorana Thromboembolic Risk Score)

\begin{tabular}{|c|c|}
\hline Patient characteristic & Score \\
\hline $\begin{array}{l}\text { Cancer } \\
\text { Very high risk: stomach, pancreas }{ }^{\mathrm{a}} \\
\text { High risk (lung, lymphoma, gynaecologic, } \\
\text { bladder, testicular, renal tumours) }\end{array}$ & $\begin{array}{l}2 \\
1\end{array}$ \\
\hline Pre-chemotherapy platelet count $\geq 350,000 / \mu \mathrm{L}$ & 1 \\
\hline $\begin{array}{l}\text { Haemoglobin level }<10 \mathrm{~g} / \mathrm{dL} \text { or use of red cell } \\
\text { growth factors }\end{array}$ & 1 \\
\hline Pre-chemotherapy leukocyte count $>11,000 / \mu \mathrm{L}$ & 1 \\
\hline Body mass index $\geq 35 \mathrm{~kg} / \mathrm{m}^{2}$ & 1 \\
\hline \multicolumn{2}{|c|}{$\begin{array}{l}\text { Calculate total score, adding points for each criterion in the } \\
\text { model }^{b}\end{array}$} \\
\hline
\end{tabular}

Abbreviation: VTE, venous thromboembolism.

an the very high-risk category, primary brain tumours were removed because patients with known brain tumours are excluded from study inclusion.

b Patients at high risk for VTE had a baseline risk score $\geq 2$.

Source: Adapted from Khorana et al. ${ }^{16}$ 
Table 2 Summary of clinical evidence highlighting the association between cancer and the risk of venous thromboembolism based on the Khorana score

\begin{tabular}{|c|c|c|c|c|c|}
\hline \multirow[t]{2}{*}{ Patient population } & \multirow{2}{*}{$\begin{array}{l}\text { Patients } \\
(N)\end{array}$} & \multirow[t]{2}{*}{ Duration } & \multicolumn{3}{|l|}{ Rate of VTE, \% } \\
\hline & & & $\begin{array}{l}\text { Low risk } \\
(\text { score }=0)\end{array}$ & $\begin{array}{l}\text { Medium risk } \\
\text { (score = 1-2) }\end{array}$ & $\begin{array}{l}\text { High risk } \\
(\text { score } \geq 3)\end{array}$ \\
\hline \multicolumn{6}{|l|}{ Retrospective studies } \\
\hline Solid tumours or malignant lymphoma ${ }^{23}$ & 112 & $2 y$ & 5.0 & 15.9 & 41.4 \\
\hline Any tumour type ${ }^{24}$ & 932 & NA & 13.0 & 17.1 & 28.2 \\
\hline Any advanced tumour type ${ }^{25}$ & 1,415 & $2 \mathrm{mo}$ & 1.5 & 4.8 & 12.9 \\
\hline Any tumour type $\mathrm{e}^{26}$ & 378 & $113 \mathrm{~d}$ & \multicolumn{2}{|c|}{3.0} & 11.1 \\
\hline Any tumour type $\mathrm{e}^{27}$ & 150 & NA & 1.9 & 3.9 & 9.1 \\
\hline Any tumour type ${ }^{28}$ & 2,782 & $1 \mathrm{y}$ & NA & $\begin{array}{l}\text { Score }>2 \text { : } \\
\text { OR: } 1.71 \\
\text { (95\% Cl: } 1.16-2.59)\end{array}$ & $\begin{array}{l}\text { OR: } 2.54 \\
\text { (95\% Cl: } 1.29-5.03 \text { ) }\end{array}$ \\
\hline Pancreatic tumours $^{29}$ & 108 & NA & NA & 14.0 & 27.0 \\
\hline Disseminated germ cell tumours ${ }^{30}$ & 254 & $11 \mathrm{y}$ & NA & NA & OR: $11.8 ; p<0.001$ \\
\hline \multicolumn{6}{|l|}{ Prospective studies } \\
\hline Any tumour type $\mathrm{s}^{31}$ & 819 & $643 \mathrm{~d}$ & 1.5 (95\% Cl: $0.6-3.9)$ & $\begin{array}{l}\text { Score }=1: \\
3.8 \text { (95\% Cl: } 1.9-7.4) \\
\text { Score = 2: } \\
9.6(95 \% \mathrm{Cl}: 6.2-14.7)\end{array}$ & $\begin{array}{l}17.7 \\
(95 \% \text { Cl: } 11.0-27.8)\end{array}$ \\
\hline Any tumour type ${ }^{32}$ & 1,097 & $3 \mathrm{mo}$ & NA & NA & $\begin{array}{l}\text { OR: } 3.5 \\
\text { (95\% Cl: 1-12.3) }\end{array}$ \\
\hline Any tumour type $\mathrm{s}^{33}$ & 35 & $3 \mathrm{mo}$ & $\mathrm{NA}$ & NA & 23.0 \\
\hline Any tumour type $\mathrm{s}^{34}$ & 580 & $3 \mathrm{mo}$ & 4.0 & NA & Score $\geq 2: 11.0$ \\
\hline Any tumour type $\mathrm{e}^{35}$ & 1,685 & $2 y$ & & $\begin{array}{l}\text { Score }=1: \\
\mathrm{HR}=3.23 \\
(95 \% \mathrm{Cl}: 1.53-6.81) \\
p=0.002 \\
\text { Score }=2: \\
\mathrm{HR}=4.63 \\
(95 \% \mathrm{Cl}: 2.20-9.75) \\
p<0.001\end{array}$ & $\begin{array}{l}\mathrm{HR}=6.47 \\
(95 \% \mathrm{Cl}: 2.99-14.00) \\
p<0.001\end{array}$ \\
\hline \multicolumn{6}{|l|}{ Pooled analysis } \\
\hline Non-Hodgkin's lymphoma ${ }^{36}$ & 1,717 & NA & 2.2 (95\% Cl: NA) & 4.5 (95\% Cl: 2.3-6.7) & $\begin{array}{l}6.6 \text { (95\% Cl: } 2.4-10.8) \\
p=0.012\end{array}$ \\
\hline
\end{tabular}

Abbreviations: Cl, confidence interval; HR, hazard ratio; NA, not applicable; OR, odds ratio; VTE, venous thromboembolism. Source: Adapted from Angelini et al. ${ }^{37}$

Rivaroxaban is a potent, oral, highly selective, direct inhibitor of factor Xa. Previous clinical studies demonstrated that rivaroxaban is effective in VTE prophylaxis in patients undergoing hip/knee replacement surgery (RECORD 1-4) and in the treatment and secondary prevention of VTE in patients with acute symptomatic DVT (EINSTEIN-DVT) or PE (EINSTEIN-PE), with an acceptable safety profile. ${ }^{40-45}$ In a pooled subgroup analysis of EINSTEIN-DVT and EINSTEIN-PE in patients with a cancer ( $8 \%$ of total population), recurrent VTE occurred in $5 \%$ of patients treated with rivaroxaban and in $7 \%$ of those receiving enoxaparin plus vitamin $\mathrm{K}$ antagonist (VKA) therapy (hazard ratio [HR]: 0.67; 95\% confidence interval [CI]: $0.35-1.30) .{ }^{43,44,46}$ Additionally, clinically relevant bleeding occurred in $14 \%$ of patients receiving rivaroxaban and in 16\% receiving enoxaparin (HR: 0.80; 95\% CI: 0.54-1.20), and major bleeding rates were 2 and $5 \%$, respectively (HR: 0.42 ; $95 \%$ CI: $0.18-0.99$ ). In a recent analysis of a quality improvement initiative to guide rivaroxaban use for cancer-associated thrombosis, the rates of major bleeding and recurrent VTE suggested safety and efficacy to be comparable with past- published experience with LMWH, with the advantage of reduced patient burden. At 6 months, the cumulative incidence of new or recurrent VTE was 4.4\% (95\% CI: $1.4-7.4 \%$ ) and major bleeding $2.2 \%$ (95\% CI: $0-4.2 \%) .{ }^{47}$ These preliminary findings are suggestive that in the prophylactic setting too, anticoagulation with rivaroxaban may reduce the risk for VTE in patients with cancer, with a favourable safety profile.

The CASSINI study has been designed to evaluate the efficacy and safety of rivaroxaban versus placebo for primary thromboprophylaxis in cancer outpatients who are receiving systemic cancer therapy and are at high risk for VTE. Highrisk patients will be identified using the Khorana score.

\section{Methods}

\section{Study Design and Setting}

CASSINI (NCT02555878) is a phase 3b, randomized, double-blind, placebo-controlled, parallel-group, multicentre study designed to compare the efficacy and safety of rivaroxaban versus placebo as primary prophylaxis of 


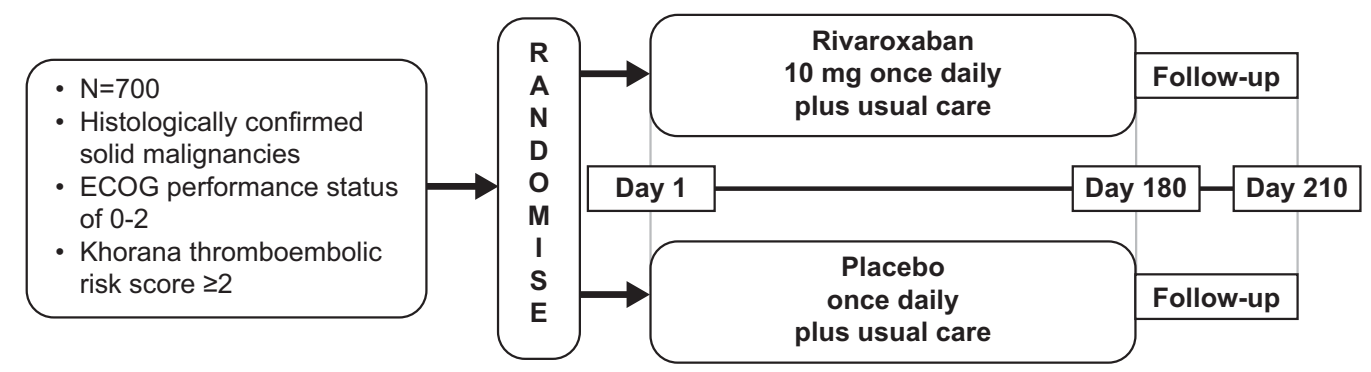

Fig. 1 CASSINI study design. ECOG, Eastern Cooperative Oncology Group.

VTE in ambulatory patients who are receiving systemic cancer treatment and are at an increased risk for VTE. This study consists of three periods: a 2-week screening period; a 180-day, double-blind treatment period; and a 30-day, post-treatment follow-up period (-Fig. 1). The duration of study participation for each patient is approximately 32 weeks. CASSINI will enrol approximately 700 patients at $180+$ study locations in North America and several countries in Europe. Patients will provide written informed consent before initiation of any study-related procedures, and the study will be conducted in accordance with the Declaration of Helsinki, Good Clinical Practice, and applicable regulatory and country-specific requirements. This study will be undertaken at each location only after the independent ethics committee/institutional review board (local/central) has given full approval.

\section{Patient Population}

Ambulatory men and women, 18 years of age and older, with various cancer types and a baseline Khorana risk score $\geq 2$, an expected survival of $>6$ months, initiating systemic cancer therapy and who are judged by the investigator as appropriate candidates for thromboprophylaxis based on their clinical status, are eligible for study participation. Patients with primary brain tumours or those at risk for bleeding are excluded (-Table 3 ).

\section{Study Treatment}

Patients will be randomized 1:1 to rivaroxaban $10 \mathrm{mg}$ orally once daily or placebo once daily for $180( \pm 3)$ days based on a computer-generated randomization schedule and stratified by tumour type (advanced pancreatic cancer [APC] or nonAPC); it is estimated that approximately $25 \%$ of the patients randomly assigned will be those with APC. Study drug is initiated within \pm 1 week of initiation of systemic cancer therapy. Study drug can be taken with or without food and should be taken at the same time each day.

Study drug treatment may be temporarily interrupted or permanently discontinued as necessary for invasive procedures or as medically needed (e.g., bleeding event or required prohibited therapy). It is recommended, when possible, that study drug be discontinued at the discretion of the investigator at least 24 hours before an invasive procedure to minimize the risk of bleeding. Bridging with parenteral anticoagulation may be considered to balance the risk of bleeding against that of VTE. Study drug should be restarted after surgical or other invasive procedures as soon as adequate haemostasis has been established (generally 24 hours for low-risk bleeding or minor surgical procedures and 48 hours for high-risk bleeding or major surgical procedures).

If the platelet count decreases to $<25 \times 10^{9} / \mathrm{L}$ for more than 1 week, then the patient will be temporarily discontinued until the platelet count returns to $\geq 25 \times 10^{9} / \mathrm{L}$.

Table 3 Major inclusion and exclusion criteria for patient selection

\begin{tabular}{|l|l|}
\hline Inclusion criteria & Exclusion criteria \\
\hline 1. $\geq 18$ y of age & 1. Diagnosis of primary brain tumour \\
\hline $\begin{array}{l}\text { 2. Histologically confirmed solid malignancy including, but } \\
\text { not limited to, pancreas, lung, stomach, colon, rectum, } \\
\text { bladder, breast, ovary, renal or lymphoma (haematologic), } \\
\text { with locally advanced or metastatic disease }\end{array}$ & 2. Known history of brain metastases \\
\hline 3. ECOG PS $0-2$ & $\begin{array}{l}\text { 3. Haematologic malignancies with the exception of } \\
\text { lymphoma }\end{array}$ \\
\hline $\begin{array}{l}\text { 4. Khorana score } \geq 2 \\
\text { 5. Adequate renal function: CrCl } \geq 30 \mathrm{~mL} / \text { min }\end{array}$ & $\begin{array}{l}\text { 4. Bleeding diathesis, haemorrhagic lesions, active bleeding } \\
\text { and other conditions with a high risk for bleeding }\end{array}$ \\
\hline $\begin{array}{l}\text { 6. Plan to initiate systemic cancer therapy within } \pm 1 \mathrm{wk} \text { of } \\
\text { receiving first dose of study drug with the intent of } \\
\text { the double-blind treatment period }\end{array}$ & $\begin{array}{l}\text { 6. Evidence of VTE on screening CU or incidental VTE } \\
\text { identified on spiral CT scans ordered primarily for staging } \\
\text { or restaging of malignancy } \leq 30 \mathrm{~d} \text { prior to randomization }\end{array}$ \\
\hline
\end{tabular}

Abbreviations: $\mathrm{CrCl}$, creatinine clearance; $\mathrm{CT}$, computed tomography; $\mathrm{CU}$, compression ultrasonography; ECOG, Eastern Cooperative Oncology Group; PS, performance status; VTE, venous thromboembolism. 
Patients should have their platelet count monitored carefully if the platelet count decreases to $<50 \times 10^{9} / \mathrm{L}$, and investigator discretion should be used. Patients should have their renal function monitored when creatinine clearance $(\mathrm{CrCl})$ drops below $<30 \mathrm{~mL} / \mathrm{min}$ and investigator discretion should be used with regard to study drug administration. If the patient's $\mathrm{CrCl}$ decreases to $<15 \mathrm{~mL} / \mathrm{min}$, then the patient should be discontinued from study drug treatment.

\section{Study Endpoints}

The primary efficacy composite endpoint is the time from randomization to the first occurrence of objectively confirmed, symptomatic, lower-extremity, proximal DVT; asymptomatic, lower-extremity, proximal DVT; symptomatic, upper-extremity DVT; symptomatic, non-fatal PE; incidental PE; or VTE-related death during the 180-day ( \pm 3 days), double-blind treatment period as adjudicated by an independent blinded clinical endpoint committee (CEC; - Table 4). Key secondary efficacy endpoints include symptomatic VTE events (DVT/PE), VTE-related deaths or all-cause mortality. Other secondary efficacy endpoints include time from randomization to the first occurrence of the individual components of the composite primary efficacy endpoint, symptomatic distal DVT, confirmed fatal/non-fatal arterial thromboembolism (ATE) events and confirmed fatal/non-fatal visceral VTE events. In addition, a composite of symptomatic, lower-extremity, proximal DVT; asymptomatic, lower-extremity, proximal DVT; symptomatic, upper-extremity DVT; non-fatal PE; incidental PE; and all-cause mortality will be assessed.
The primary safety endpoint is the time to a major bleeding event as defined by the International Society on Thrombosis and Haemostasis (ISTH). Bleeding events will be classified using protocol-specified definitions for major, clinically relevant non-major or minor bleeding. Secondary safety endpoints include percentages of clinically relevant non-major bleeding, minor bleeding and any bleeding.

Exploratory endpoints include biomarkers related to inflammation and hypercoagulability (including D-dimer, P-selectin and tissue factor), pharmacokinetics and exposure response to rivaroxaban and health care resource utilization.

\section{Study Procedures}

At the screening visit (day -14 to -1 ), bilateral, lowerextremity, venous duplex compression ultrasonography (CU) will be performed (-Table 5). Patients with baseline DVT on screening CU or incidental DVT or PE identified during routine care imaging (e.g., spiral computed tomography [CT] scans used primarily for staging or restaging of malignancy) within 30 days prior to randomization will not be eligible for randomization.

Study visits will occur at week 8 ( \pm 7 days), week 16 ( \pm 7 days) and day 180 /end of treatment (EOT; \pm 3 days) during the double-blind treatment period. Mandatory CU will be performed at each visit. After a 30-day post-treatment follow-up period, all patients, including those who discontinued study drug before day 180 ( \pm 3 days), will be contacted for a day 210 ( \pm 7 days)/end-of-study (EOS) follow-up visit. Vital status (i.e., dead, alive or lost to follow-up) as well as clinical status review

Table 4 CASSINI study endpoints

\begin{tabular}{|c|c|}
\hline \multicolumn{2}{|l|}{ Efficacy } \\
\hline Primary & $\begin{array}{l}\text { - Composite of time from randomization to first occurrence of symptomatic, lower-extremity, proximal DVT; } \\
\text { asymptomatic, lower-extremity, proximal DVT; symptomatic, upper-extremity DVT; symptomatic, nonfatal } \\
\text { PE; incidental PE; or VTE-related death during the } 180-\mathrm{d}( \pm 3 \mathrm{~d}) \text {, double-blind treatment period }\end{array}$ \\
\hline \multirow{3}{*}{$\begin{array}{l}\text { Key } \\
\text { secondary }\end{array}$} & - Symptomatic VTE events \\
\hline & - VTE-related deaths \\
\hline & - All-cause mortality \\
\hline \multirow[t]{4}{*}{ Other } & $\begin{array}{l}\text { - Time from randomization to first occurrence of individual components of the composite primary efficacy } \\
\text { endpoint }\end{array}$ \\
\hline & - Confirmed fatal/non-fatal arterial thromboembolism events \\
\hline & - Confirmed fatal/non-fatal visceral VTE events \\
\hline & $\begin{array}{l}\text { - Composite of symptomatic, lower-extremity, proximal DVT; asymptomatic, lower-extremity, proximal DVT; } \\
\text { symptomatic, upper-extremity DVT; symptomatic, non-fatal PE; incidental PE; and all-cause mortality }\end{array}$ \\
\hline \multicolumn{2}{|l|}{ Safety } \\
\hline Primary & - Time to a major bleeding event as defined by the ISTH \\
\hline Secondary & - Percentages of clinically relevant non-major bleeding, minor bleeding and any bleeding \\
\hline \multicolumn{2}{|l|}{ Exploratory } \\
\hline & - Inflammation and hypercoagulability biomarkers (e.g., D-dimer, P-selectin and tissue factor) \\
\hline & - Pharmacokinetics and exposure response to rivaroxaban \\
\hline & - Health care resource utilization \\
\hline
\end{tabular}

Abbreviations: DVT, deep-vein thrombosis; ISTH, International Society on Thrombosis and Haemostasis; PE, pulmonary embolism; VTE, venous thromboembolism. 
for suspected outcome and safety bleeding events will be completed. Adverse events (AEs) and concomitant medications will be collected.

Blood samples will be collected at screening, weeks 8 and 16 , and day 180/EOT to measure levels of circulating D-dimer, P-selectin and tissue factor.

\section{Study Oversight}

A steering committee has been formed that has overall responsibility for the conduct and reporting of the study. Suspected DVT and non-fatal PE occurring during the double-blind treatment phase and the 30-day follow-up phase will be centrally adjudicated by an independent, blinded CEC. Additionally, incidental DVT or PE, identified from routine care imaging during the same time period, will be adjudicated as asympto- matic DVT or PE events. Finally, any clinical event that suggests the possibility that a major or clinically relevant non-major bleeding event has occurred will be sent for adjudication. An Independent Data Monitoring Committee (IDMC) will ensure that patient safety is not compromised.

\section{Sample Size and Statistical Analyses}

Although estimates of VTE event rates vary, most previous clinical studies, which were generally between 3 and 4 months in duration, reported relative risk reductions between 50 and $64 \%$ when ambulatory patients receiving systemic cancer therapy were also treated with anticoagulant therapy. ${ }^{48}$ Estimates of assumed VTE events are derived from the Vienna CATS (Cancer and Thrombosis Study) group, which used the Khorana score to monitor 819 ambulatory patients with

Table 5 Schedule of assessments

\begin{tabular}{|c|c|c|c|c|c|c|}
\hline \multirow{3}{*}{$\begin{array}{l}\text { Period } \\
\text { Month }\end{array}$} & \multirow[t]{3}{*}{ Screening } & \multicolumn{4}{|c|}{ Double-blind treatment } & \multirow{3}{*}{$\begin{array}{l}\begin{array}{l}\text { Post-treatment } \\
\text { (follow-up) }\end{array} \\
\begin{array}{l}\text { End-of-study } \\
\text { follow-up }( \pm 7 \mathrm{~d})\end{array} \\
7\end{array}$} \\
\hline & & \multirow{2}{*}{$\begin{array}{l}\text { Randomization } \\
-\end{array}$} & \multicolumn{2}{|c|}{$\begin{array}{l}\text { Every 8-wk visits } \\
( \pm 7 \mathrm{~d})\end{array}$} & \multirow{2}{*}{$\begin{array}{l}\text { End-of-treatment } \\
\text { visit }( \pm 3 \mathrm{~d}) \\
6\end{array}$} & \\
\hline & & & 2 & 4 & & \\
\hline Day/Week & Day -14 to -1 & Day 1 & Week 8 & Week 16 & Day 180 & Day 210 \\
\hline \multicolumn{7}{|l|}{ Eligibility } \\
\hline $\begin{array}{l}\text { Obtain informed } \\
\text { consent }\end{array}$ & $\mathrm{X}$ & & & & & \\
\hline $\begin{array}{l}\text { Apply inclusion/ } \\
\text { exclusion criteria }\end{array}$ & $x$ & & & & & \\
\hline Demographics & $x$ & & & & & \\
\hline Relevant medical history & $x$ & & & & & \\
\hline $\begin{array}{l}\text { Disease staging } \\
\text { (using TNM system } \\
\text { [solid tumours] or Ann } \\
\text { Arbor system } \\
\text { [lymphoma]) }\end{array}$ & $x$ & & & & & \\
\hline $\begin{array}{l}\text { Perform physical } \\
\text { examination (record } \\
\text { height/weight/BMI) }\end{array}$ & $x$ & & & & & \\
\hline $\begin{array}{l}\text { Coagulation tests } \\
\text { (PT, aPTT and INR) }\end{array}$ & $x$ & & & & & \\
\hline Record pre-study drugs & $x$ & $x$ & & & & \\
\hline $\begin{array}{l}\text { Record Khorana } \\
\text { thromboembolic } \\
\text { risk score }\end{array}$ & $x$ & & & & & \\
\hline Randomization & & $x$ & & & & \\
\hline \multicolumn{7}{|l|}{ Study drug administration } \\
\hline $\begin{array}{l}\text { Contact IWRS for study } \\
\text { drug bottle number to } \\
\text { dispense }\end{array}$ & & $x$ & $x$ & $x$ & & \\
\hline $\begin{array}{l}\text { Dispense study drug/ } \\
\text { provide instructions }\end{array}$ & & $x$ & $X$ & $X$ & & \\
\hline $\begin{array}{l}\text { Perform study drug } \\
\text { accountability/ } \\
\text { compliance }\end{array}$ & & & $x$ & $x$ & $x$ & \\
\hline
\end{tabular}


Table 5 (Continued)

\begin{tabular}{|c|c|c|c|c|c|c|}
\hline \multirow[t]{2}{*}{ Period } & \multirow[t]{2}{*}{ Screening } & \multicolumn{4}{|c|}{ Double-blind treatment } & \multirow{2}{*}{$\begin{array}{l}\begin{array}{l}\text { Post-treatment } \\
\text { (follow-up) }\end{array} \\
\text { End-of-study } \\
\text { follow-up }( \pm 7 \mathrm{~d})\end{array}$} \\
\hline & & Randomization & \multicolumn{2}{|c|}{$\begin{array}{l}\text { Every 8-wk visits } \\
\text { ( } \pm 7 \text { d) }\end{array}$} & $\begin{array}{l}\text { End-of-treatment } \\
\text { visit }( \pm 3 \mathrm{~d})\end{array}$ & \\
\hline \multicolumn{7}{|l|}{ Safety assessments } \\
\hline Urine pregnancy test & $x$ & & & & $x$ & \\
\hline $\begin{array}{l}\text { Record vital signs } \\
\text { including weight }\end{array}$ & $x$ & $x$ & $x$ & $x$ & $x$ & \\
\hline $\begin{array}{l}\text { Record ECOG } \\
\text { performance status }\end{array}$ & $x$ & $x$ & $x$ & $x$ & $x$ & \\
\hline $\begin{array}{l}\text { Record central venous } \\
\text { catheter status }\end{array}$ & $x$ & $x$ & $x$ & $x$ & $x$ & \\
\hline $\begin{array}{l}\text { Collect laboratory } \\
\text { samples (haematology, } \\
\text { serum chemistry) }\end{array}$ & $x$ & & $x$ & $x$ & $\mathrm{X}$ & \\
\hline Calculated eGFR & $x$ & & $x$ & $x$ & $x$ & \\
\hline $\begin{array}{l}\text { Clinical events relevant } \\
\text { to safety endpoints } \\
\text { (bleeding events) }\end{array}$ & & & $x$ & $x$ & $x$ & $x$ \\
\hline Adverse events & $x$ & $x$ & $x$ & $x$ & $x$ & $x$ \\
\hline Concomitant therapy & & $x$ & $x$ & $x$ & $x$ & $x$ \\
\hline \multicolumn{7}{|l|}{ Efficacy assessments } \\
\hline $\begin{array}{l}\text { Perform bilateral, } \\
\text { lower-extremity venous } \\
\text { duplex compression } \\
\text { ultrasonography }\end{array}$ & $x$ & & $\mathrm{X}$ & $x$ & $x$ & \\
\hline $\begin{array}{l}\text { Clinical events relevant } \\
\text { to efficacy endpoints }\end{array}$ & & & $x$ & $x$ & $x$ & $x$ \\
\hline $\begin{array}{l}\text { Telephone follow-up for } \\
\text { vital status }\end{array}$ & & & & & & $x$ \\
\hline \multicolumn{7}{|l|}{ Exploratory assessments } \\
\hline Biomarker sample & $x$ & & $x$ & $x$ & $x$ & \\
\hline Pharmacokinetic sample & & & $x$ & & & \\
\hline
\end{tabular}

Abbreviations: aPTT, activated partial thromboplastin time; BMI, body mass index; ECOG, Eastern Cooperative Oncology Group; eGFR, estimated glomerular filtration rate; INR, international normalised ratio; IWRS, interactive web response system; PT, prothrombin time; TNM, tumour, node, metastasis.

cancer for symptomatic VTE. ${ }^{31}$ The Kaplan-Meier analysis demonstrated that the cumulative probability of VTE after 6 months was $17.7 \%$ (95\% CI: $11.0-27.8 \% ; N=93$ ) in patients with a Khorana score $\geq 3$ and $9.6 \%$ (95\% CI: $6.2-14.7 \%$; $N=221$ ) in patients with a Khorana score of $2 .^{31}$ Taken together, these results and those of smaller randomized controlled trials support a projected symptomatic event rate at 180 days of at least 9.5\%. Adjudication of asymptomatic proximal DVT and incidental PE is estimated to add 5 to $8 \%$, supporting a $14.5 \%$ incidence rate in the placebo group.

Assuming a cumulative incidence rate of $14.5 \%$ in the placebo group and $6.0 \%$ in the rivaroxaban group for the primary composite endpoint, a total of approximately 700 patients will be required to demonstrate an approximately $60 \%$ relative risk reduction in the primary efficacy endpoint with a two-sided, type 1 error rate of 5\%, >90\% statistical power and assuming a $20 \%$ discontinuation rate.
The CASSINI study will evaluate the hypothesis that prophylaxis with rivaroxaban will be superior to placebo for the composite primary efficacy endpoint. The primary and key secondary efficacy endpoint analyses will be based on the intent-to-treat population, which consists of all randomized patients with valid informed consent. All safety endpoints will be analysed using the safety analysis set, which consists of all randomized patients who receive at least one dose of study drug.

The primary composite endpoint and key secondary efficacy endpoint analyses will be performed on a time-to-firstevent basis, using a stratified Cox proportional hazard model and treatment group as a categorical variable. Patients who have no primary efficacy events during the double-blind treatment period, who are lost to follow-up, who die because of non-VTE-related reasons or who withdraw informed consent before the EOT will be censored. To account for 
competing risks (i.e., deaths from causes other than VTE for efficacy or fatal bleeding for safety), a cumulative incidence approach using Gray's two-sample test (two-sided, type 1 error rate of 5\%) will be adopted. Associated HR and 95\% CI will be calculated using a Fine and Gray regression model. Kaplan-Meier estimates adjusted for competing risk over time will be plotted for time-to-event variables.

Statistical comparison of the primary safety endpoint will be performed using a Cox proportional hazards model with treatment as a covariate. Additionally, the frequency of bleeding events in each treatment group will be summarized. Secondary safety endpoints including AEs and laboratory events will also be summarized.

\section{Discussion}

CASSINI will be the first randomized clinical study to compare the efficacy and safety of rivaroxaban, an oral anticoagulant that has undergone rigorous investigation, with placebo in the prevention of VTE in high-risk, ambulatory patients with cancer receiving systemic cancer therapy. At present, no other anticoagulant is approved for primary thromboprophylaxis in outpatients with cancer, and inclusion of a placebo arm will allow a clear determination of the clinical value of rivaroxaban in this setting. Importantly, CASSINI will enrol only patients with cancer who are at increased risk of VTE, as determined by the previously validated Khorana risk score. This approach is consistent with the 2013 and 2014 American Society of Clinical Oncology VTE guidelines, which recommend the use of this risk score rather than individual risk factors to identify patients at increased risk. ${ }^{3,38}$

Patients with primary brain tumours are excluded from CASSINI because of an increased risk of intracranial bleeding demonstrated in a prior prophylaxis study. The PRODIGE study (NCT00135876) demonstrated that dalteparin LMWH thromboprophylaxis was associated with a higher rate of intracranial bleeding compared with placebo in patients with newly diagnosed malignant glioma (5.1 vs. $1.2 \%$ at 12 months). ${ }^{49}$ Although this is an area requiring additional investigation, given the known higher rates of bleeding, we believe that this issue is best addressed in a separate, specific study and have chosen to exclude patients with brain tumours from the CASSINI trial.

Supportive evidence from previous studies suggests that rivaroxaban $10 \mathrm{mg}$ daily may be appropriate for effective VTE prevention in high-risk settings. Venous thromboembolism prophylaxis studies in patients undergoing knee or hip replacement surgery demonstrated that rivaroxaban $10 \mathrm{mg}$ daily provides an absolute reduction in VTE risk ranging from 2.6 to $9.2 \%$ and has an acceptable safety profile. ${ }^{40-42}$ Data from the EINSTEIN sub-studies provide some experience with the use of rivaroxaban 15 to $20 \mathrm{mg}$ in patients with cancer in the treatment or secondary prophylaxis settings. ${ }^{43,44,46,50}$ Clinically relevant bleeding in patients treated with rivaroxaban 15 to $20 \mathrm{mg}$ was similar to the rate reported in the enoxaparin/VKA antagonist group, and there were significantly fewer major bleeding events in the rivaroxaban treatment group. ${ }^{43,44,46} \mathrm{~A}$ recent quality assurance initiative to guide rivaroxaban use in cancer-associated thrombosis also suggested efficacy/safety profile to be at least non-inferior to LMWH, with the added benefit of reduced patient burden. ${ }^{47}$

The duration of previous primary VTE prophylaxis studies was generally between 3 and 4 months. However, given the cumulative nature of VTE risk in patients with cancer receiving chemotherapy, ${ }^{9}$ the risk of VTE persists beyond this initial time period. The use of a once-daily oral agent allows a patient-friendly approach to extending the period of prophylaxis than has been previously studied. CASSINI was designed to extend the observation window to 6 months after initiation of a new systemic cancer regimen to evaluate whether rivaroxaban can effectively and safely prevent VTE events in patients who typically undergo several cycles of systemic cancer therapy. This approach will allow for a more confident assessment of the benefit-risk profile of rivaroxaban thromboprophylaxis in this population.

Perioperative management of patients who require an elective surgical or other invasive procedure is an area of ongoing uncertainty. There is a lack of data specifically in the high-risk cancer population. Current clinical guidelines from the American Heart Association, the American College of Cardiology, the Heart Rhythm Society and the American College of Chest Physicians recommend that patients at highest risk for thromboembolism without excessive bleeding risk should consider bridging. ${ }^{51,52}$ Thus, bridging anticoagulation may be considered in CASSINI, which is enrolling cancer patients at high risk for VTE, in accordance with these recommendations.

In the CASSINI study, DVT will be diagnosed using CU, the standard method for the diagnosis of this condition because of its low level of invasiveness and high sensitivity. ${ }^{53} \mathrm{~A}$ prospective cohort study of patients undergoing total hip or knee arthroplasty indicated that CU has a positive predictive value ( 71 vs. $25 \%$ for clinical examination) and sensitivity ( 83 vs. $11 \%$ for clinical examination). ${ }^{54}$ The Joint American Academy of Family Physicians/American College of Physicians Panel on DVT/PE recommends the use of CU for patients with at least an intermediate probability of lower-extremity DVT. ${ }^{55}$

An important feature of the CASSINI study is the use of screening to detect asymptomatic VTE, which is relatively common and is associated with higher mortality similarly to patients with symptomatic VTE. An analysis of 1,151 radiologic examinations of 135 APC patients demonstrated that incidental events comprised $33.3 \%$ of PEs, $21.4 \%$ of DVTs and $100 \%$ of visceral VTEs. Deep-vein thrombosis (HR: 25; 95\% CI: 10-63; $p<0.0001$ ), PE (HR: 8.9; 95\% CI: 2.5-31.7; $p=0.007$ ) and visceral events (HR: 2.6 ; 95\% CI: $1.6-4.2 ; p=0.0001$ ) were all independently associated with mortality. There was no significant difference between asymptomatic and symptomatic events in terms of conditional survival at 3 or 6 months after diagnosis. ${ }^{56}$ Consistent with the documented correlation between asymptomatic VTE and higher mortality, the U.S. and EU (European Union) regulatory authorities accept the use of asymptomatic VTE as a relevant endpoint in registrational studies.

CASSINI is part of CALLISTO, a new global research programme that will evaluate rivaroxaban across the spectrum of prevention and treatment of cancer-associated VTE. 
CALLISTO will involve more than 4,000 patients worldwide and will comprise nine initiatives, including several clinical studies, registries, a survey and expert guidance. ${ }^{57}$ The CASSINI study will provide the first data related to the use of longer-term, oral anticoagulation for the primary prevention of VTE in high-risk, ambulatory patients with cancer who are receiving systemic cancer therapy. The only other primary VTE prevention study is the phase 2 AVERT study (NCT02048865), which will evaluate the efficacy and safety of the oral anticoagulant apixaban for the prevention of VTE in high-risk ambulatory patients with cancer. Treatment with an effective and well-tolerated oral anticoagulant, administered once daily, has the potential to reduce the burden of VTE and its consequences for patients with cancer.

\section{What is known about this topic?}

- Patients with cancer are at a four- to sevenfold greater risk for venous thromboembolism (VTE) compared with individuals without cancer. The risk differs among cancer patients, and the Khorana risk score allows for identification of patients with cancer at increased risk for VTE.

- Cancer-associated VTE occurs primarily in the outpatient setting, and VTE is the second leading cause of death in ambulatory patients with cancer.

- Previous studies of thromboprophylaxis with LMWH (low-molecular-weight heparins) in ambulatory patients with cancer have demonstrated that anticoagulation is associated with a significant relative risk reduction in VTE, but current clinical guidelines do not recommend routine outpatient VTE prophylaxis because the overall benefit-to-risk profile in an unselected patient population is uncertain. At present, no anticoagulant is approved for primary thromboprophylaxis in outpatients with cancer.

\section{What does this paper add?}

- The CASSINI trial will be the first randomized clinical study designed to evaluate the efficacy and safety of rivaroxaban, an oral anticoagulant, versus placebo for prevention of VTE in high-risk, ambulatory patients with cancer receiving systemic cancer therapy.

- It will provide the first data related to the use of longerterm, oral anticoagulation for the primary prevention of VTE in this setting.

\section{Conflict of Interests}

A.A.K. reports honoraria for co-chairing the steering committee for CASSINI from Janssen, and consulting fees from Bayer. S.V.-R. reports being a member of the Advisory Board for Janssen and has received compensation for consulting. $\mathrm{N}$. M.K. reports being a research consultant for Janssen and Hospira, and reports spouse receiving research funds from Amgen. T.W. reports serving on Advisory Committees for CALLISTO and Janssen. H.L. reports serving as a consultant for Janssen Pharmaceuticals. G.S. has received funding for research by Janssen Pharmaceuticals. C.B. reports serving on the Steering Committee and as an Advisory Council member for the CASSINI trial-Johnson \& Johnson. E.M.O. reports receiving consulting reimbursement from Janssen. R.M. reports receiving a research grant from Bristol-Myers Squibb. J.E. reports receiving grant and honoraria support from AstraZeneca, Bayer, Boehringer Ingelheim, BristolMyers Squibb, Pfizer, Sanofi-Aventis, Daiichi-Sankyo, Janssen and GlaxoSmithKline. C.V.D. is an employee of Janssen Research \& Development, LLC. K.B. is an employee of Janssen Pharmaceuticals, LLC. F.D. reports serving as a consultant for Janssen Pharmaceuticals; study responsible physician for the CASSINI trial. A.K. reports receiving grants and/or honoraria support from Bayer, Daiichi-Sankyo, Boehringer Ingelheim, Sanofi and Janssen. H.R. reports research grant from Bayer and honoraria from Boehringer Ingelheim, Bayer, Pfizer, Daiichi-Sankyo and Leo Pharma. R.D.P. reports no conflicts of interest. G.H.L. reports no conflicts of interest.

\section{Acknowledgements}

Dr. Khorana acknowledges additional research support from the National Heart, Lung, and Blood Institute (1R34HL127156), the Sondra and Stephen Hardis Chair in Oncology Research, the Cleveland Clinic Center of Excellence Grant and the Scott Hamilton CARES Initiative.

This study was sponsored by Janssen Research \& Development, LLC, and Bayer Pharma AG. Financial support for medical editorial assistance was provided by Janssen Research \& Development, LLC, and Bayer Pharma AG. We thank Ann Marie Fitzmaurice, PhD, ProEd Communications, Inc., for medical editorial assistance with this manuscript.

\section{References}

1 Kearon C, Akl EA, Comerota AJ, et al. Antithrombotic therapy for VTE disease: Antithrombotic Therapy and Prevention of Thrombosis, 9th ed: American College of Chest Physicians EvidenceBased Clinical Practice Guidelines. Chest 2012;141(2 Suppl): e419S-e494S

2 Kearon C, Akl EA, Ornelas J, et al. Antithrombotic therapy for VTE disease: CHEST Guideline and Expert Panel Report. Chest 2016; 149(02):315-352

3 Lyman GH, Khorana AA, Kuderer NM, et al; American Society of Clinical Oncology Clinical Practice. Venous thromboembolism prophylaxis and treatment in patients with cancer: American Society of Clinical Oncology clinical practice guideline update. J Clin Oncol 2013;31(17):2189-2204

4 Streiff MB, Holmstrom B, Ashrani A, et al. Cancer-associated venous thromboembolic disease, version 1.2015. J Natl Compr Canc Netw 2015;13(09):1079-1095

5 Blom JW, Doggen CJ, Osanto S, Rosendaal FR. Malignancies, prothrombotic mutations, and the risk of venous thrombosis. JAMA 2005;293(06):715-722

6 Heit JA, Silverstein MD, Mohr DN, Petterson TM, O'Fallon WM, Melton LJ III. Risk factors for deep vein thrombosis and pulmonary embolism: a population-based case-control study. Arch Intern Med 2000;160(06):809-815

7 Blom JW, Vanderschoot JP, Oostindiër MJ, Osanto S, van der Meer FJ, Rosendaal FR. Incidence of venous thrombosis in a large cohort of 66,329 cancer patients: results of a record linkage study. J Thromb Haemost 2006;4(03):529-535 
8 Chew HK, Wun T, Harvey D, Zhou H, White RH. Incidence of venous thromboembolism and its effect on survival among patients with common cancers. Arch Intern Med 2006;166(04): 458-464

9 Lyman GH, Eckert L, Wang Y, Wang H, Cohen A. Venous thromboembolism risk in patients with cancer receiving chemotherapy: a real-world analysis. Oncologist 2013;18(12):1321-1329

10 Khorana AA, Francis CW, Culakova E, Kuderer NM, Lyman GH. Thromboembolism is a leading cause of death in cancer patients receiving outpatient chemotherapy. J Thromb Haemost 2007; 5(03):632-634

11 Khorana AA, Dalal MR, Lin J, Connolly GC. Health care costs associated with venous thromboembolism in selected high-risk ambulatory patients with solid tumors undergoing chemotherapy in the United States. Clinicoecon Outcomes Res 2013; 5:101-108

12 Maraveyas A, Waters J, Roy R, et al. Gemcitabine versus gemcitabine plus dalteparin thromboprophylaxis in pancreatic cancer. Eur J Cancer 2012;48(09):1283-1292

13 Riess H, Pelzer U, Deutschinoff G, et al. A prospective, randomized trial of chemotherapy with or without the low molecular weight heparin (LMWH) enoxaparin in patients (pts) with advanced pancreatic cancer (APC): results of the CONKO 004 trial. J Clin Oncol 2009;27(Suppl):18S. Abstract LBA4506

14 Agnelli G, George DJ, Kakkar AK, et al; SAVE-ONCO Investigators. Semuloparin for thromboprophylaxis in patients receiving chemotherapy for cancer. N Engl J Med 2012;366(07):601-609

15 Agnelli G, Gussoni G, Bianchini C, et al; PROTECHT Investigators. Nadroparin for the prevention of thromboembolic events in ambulatory patients with metastatic or locally advanced solid cancer receiving chemotherapy: a randomised, placebo-controlled, double-blind study. Lancet Oncol 2009;10(10):943-949

16 Khorana AA, Kuderer NM, Culakova E, Lyman GH, Francis CW. Development and validation of a predictive model for chemotherapy-associated thrombosis. Blood 2008;111(10):4902-4907

17 George D, Agnelli G, Fisher W, et al. Venous thromboembolism (VTE) prevention with semuloparin in cancer patients initiating chemotherapy: benefit-risk assessment by VTE risk in SAVEONCO. Blood (ASH Annual Meeting Abstracts) 2011; 118: Abstract 206

18 Khorana AA, Herman K, Rubens D, Francis CW. A predictive risk score for cancer-associated thrombosis: role of screening in a prospective study. Blood (ASH Annual Meeting Abstracts) 2010; Abstract 3173

19 Martín AJ, Ziyatdinov A, Rubio VC, et al. PO-04 - A new genetic risk score for predicting venous thromboembolic events in cancer patients receiving chemotherapy. Thromb Res 2016;140(Suppl 1): S177-S178

20 Kuderer NM, Culakova E, Lyman GH, Francis C, Falanga A, Khorana AA. A validated risk score for venous thromboembolism is predictive of cancer progression and mortality. Oncologist 2016; 21(07):861-867

21 Panizo E, Alfonso A, García-Mouriz A, et al. Factors influencing the use of thromboprophylaxis in cancer outpatients in clinical practice: a prospective study. Thromb Res 2015;136(06): $1145-1148$

22 Crowley MP, Eustace JA, O'Shea SI, Gilligan OM. Venous thromboembolism in patients with myeloma: incidence and risk factors in a "real-world" population. Clin Appl Thromb Hemost 2014;20 (06):600-606

23 Kearney JC, Rossi S, Glinert K, Henry DH. Venous thromboembolism (VTE) and survival in a cancer chemotherapy outpatient clinic: a retrospective chart review validation of a VTE predictive model. Blood 2009; 114:2503

24 Moore RA, Adel N, Riedel E, et al. High incidence of thromboembolic events in patients treated with cisplatin-based chemotherapy: a large retrospective analysis. J Clin Oncol 2011;29(25): 3466-3473
25 Mandala M, Clerici M, Corradino I, et al. Incidence, risk factors and clinical implications of venous thromboembolism in cancer patients treated within the context of phase I studies: the 'SENDO experience'. Ann Oncol 2012;23(06):1416-1421

26 Verso M, Agnelli G, Barni S, Gasparini G, LaBianca R. A modified Khorana risk assessment score for venous thromboembolism in cancer patients receiving chemotherapy: the Protecht score. Intern Emerg Med 2012;7(03):291-292

27 Sharma D, Kim SY, Henry D. Assessing a prognostic model for predicting VTE occurrence in cancer patients. J Clin Oncol 2012; 30(Suppl):Abstract 1577

28 Patell R, Rybicki LA, Elson P, et al. Predicting venous thromboembolism in hospitalized cancer patients: a risk assessment tool. J Clin Oncol 2016;34(Suppl):Abstract 6598.

29 Price LH, Nguyen MB, Picozzi VJ, Kozarek RA. Portal vein thrombosis in pancreatic cancer: natural history, risk factors and implications for patient management. 2010 ASCO Gastrointestinal Cancers Symposium. Abstract 143

30 Srikanthan A, Tran B, Beausoleil M, et al. Large retroperitoneal lymphadenopathy as a predictor of venous thromboembolism in patients with disseminated germ cell tumors treated with chemotherapy. J Clin Oncol 2015;33(06):582-587

31 Ay C, Dunkler D, Marosi C, et al. Prediction of venous thromboembolism in cancer patients. Blood 2010;116(24):5377-5382

32 Hohl Moinat C, Périard D, Grueber A, et al. Predictors of venous thromboembolic events associated with central venous port insertion in cancer patients. J Oncol 2014;2014:743181

33 Khorana AA, Rubens D, Francis CW. Screening high-risk cancer patients for VTE: a prospective observational study. Thromb Res 2014;134(06):1205-1207

34 Lustig DB, Rodriguez R, Wells PS. Implementation and validation of a risk stratification method at the Ottawa Hospital to guide thromboprophylaxis in ambulatory cancer patients at intermediate-high risk for venous thrombosis. Thromb Res 2015;136(06):1099-1102

35 Posch F, Riedl J, Reitter EM, et al. Hypercoagulabilty, venous thromboembolism, and death in patients with cancer. A multistate model. Thromb Haemost 2016;115(04):817-826

36 Santi RM, Ceccarelli M, Catania G, et al. PO-03 - Khorana score and histotype predict the incidence of early venous thromboembolism (VTE) in non-Hodgkin lymphoma (NHL). A pooled data analysis of twelve clinical trials of Fondazione Italiana Linfomi (FIL). Thromb Res 2016;140(Suppl 1):S177

37 Angelini D, Khorana AA. Risk assessment scores for cancerassociated venous thromboembolic disease. Semin Thromb Hemost 2017;43(05):469-478

38 Lyman GH, Bohlke K, Khorana AA, et al; American Society of Clinical Oncology. Venous thromboembolism prophylaxis and treatment in patients with cancer: American Society of Clinical Oncology Clinical Practice Guideline update 2014. J Clin Oncol 2015;33(06):654-656

39 Mandalà M, Falanga A, Roila F; ESMO Guidelines Working Group. Management of venous thromboembolism (VTE) in cancer patients: ESMO Clinical Practice Guidelines. Ann Oncol 2011;22 (Suppl 6):vi85-vi92

40 Eriksson BI, Borris LC, Friedman RJ, et al; RECORD1 Study Group. Rivaroxaban versus enoxaparin for thromboprophylaxis after hip arthroplasty. N Engl J Med 2008;358(26):2765-2775

41 Kakkar AK, Brenner B, Dahl OE, et al; RECORD2 Investigators. Extended duration rivaroxaban versus short-term enoxaparin for the prevention of venous thromboembolism after total hip arthroplasty: a double-blind, randomised controlled trial. Lancet 2008;372(9632):31-39

42 Lassen MR, Ageno W, Borris LC, et al; RECORD3 Investigators. Rivaroxaban versus enoxaparin for thromboprophylaxis after total knee arthroplasty. N Engl J Med 2008;358(26):2776-2786

43 Bauersachs R, Berkowitz SD, Brenner B, et al; EINSTEIN Investigators. Oral rivaroxaban for symptomatic venous thromboembolism. N Engl J Med 2010;363(26):2499-2510 
44 Büller HR, Prins MH, Lensin AW, et al; EINSTEIN-PE Investigators. Oral rivaroxaban for the treatment of symptomatic pulmonary embolism. N Engl J Med 2012;366(14):1287-1297

45 Turpie AG, Lassen MR, Davidson BL, et al; RECORD4 Investigators. Rivaroxaban versus enoxaparin for thromboprophylaxis after total knee arthroplasty (RECORD4): a randomised trial. Lancet 2009;373(9676):1673-1680

46 Prins MH, Lensing AW, Brighton TA, et al. Oral rivaroxaban versus enoxaparin with vitamin $\mathrm{K}$ antagonist for the treatment of symptomatic venous thromboembolism in patients with cancer (EINSTEINDVT and EINSTEIN-PE): a pooled subgroup analysis of two randomised controlled trials. Lancet Haematol 2014;1(01):e37-e46

47 Mantha S, Laube E, Miao Y, et al. Safe and effective use of rivaroxaban for treatment of cancer-associated venous thromboembolic disease: a prospective cohort study. J Thromb Thrombolysis 2017;43(02):166-171

48 Khorana AA. Cancer-associated thrombosis: updates and controversies. Hematology (Am Soc Hematol Educ Program) 2012; 2012:626-630

49 Perry JR, Julian JA, Laperriere NJ, et al. PRODIGE: a randomized placebo-controlled trial of dalteparin low-molecular-weight heparin thromboprophylaxis in patients with newly diagnosed malignant glioma. J Thromb Haemost 2010;8(09):1959-1965

50 Cohen AT, Spiro TE, Büller HR, et al; MAGELLAN Investigators. Rivaroxaban for thromboprophylaxis in acutely ill medical patients. N Engl J Med 2013;368(06):513-523

51 Douketis JD, Spyropoulos AC, Spencer FA, et al. Perioperative management of antithrombotic therapy: Antithrombotic Therapy and Prevention of Thrombosis, 9th ed: American College of Chest Physicians Evidence-Based Clinical Practice Guidelines. Chest 2012;141:e326S-e350S

52 January CT, Wann LS, Alpert JS, et al; American College of Cardiology/American Heart Association Task Force on Practice Guidelines. 2014 AHA/ACC/HRS guideline for the management of patients with atrial fibrillation: a report of the American College of Cardiology/American Heart Association Task Force on Practice Guidelines and the Heart Rhythm Society. J Am Coll Cardiol 2014; 64(21):e1-e76

53 Mack WJ, Ducruet AF, Hickman ZL, et al. Doppler ultrasonography screening of poor-grade subarachnoid hemorrhage patients increases the diagnosis of deep venous thrombosis. Neurol Res 2008;30(09):889-892

54 Robinson KS, Anderson DR, Gross M, et al. Accuracy of screening compression ultrasonography and clinical examination for the diagnosis of deep vein thrombosis after total hip or knee arthroplasty. Can J Surg 1998;41(05):368-373

55 Wang CJ, Wang JW, Weng LH, Hsu CC, Lo CF. Outcome of calf deepvein thrombosis after total knee arthroplasty. J Bone Joint Surg Br 2003;85(06):841-844

56 Menapace LA, Peterson DR, Berry A, Sousou T, Khorana AA. Symptomatic and incidental thromboembolism are both associated with mortality in pancreatic cancer. Thromb Haemost 2011;106(02):371-378

57 Bach M, Bauersachs R. Spotlight on advances in VTE management: CALLISTO and EINSTEIN CHOICE. Thromb Haemost 2016; 116(Suppl 2):S24-S32 